\title{
Prevalence and factors associated with mental health problems among children with asthma: A hospital-based study
}

DMA Dahanayake, GS Wijethunge, VA de Silva

\section{Abstract \\ Background}

Childhood asthma is associated with emotional and behavioural problems. The prevalence and factors associated with psychological problems in childhood asthma have not been studied in Sri Lanka.

\section{Aims}

The aim of this study was to describe the prevalence and factors associated with development of emotional and behavioural problems among children with asthma, presenting to outpatient follow up clinics.

\section{Methods}

This was a hospital based cross sectional descriptive study using systematic random sampling $(n=250)$. The parents completed the Strengths and Difficulties Questionnaire (Sinhala version) and children with borderline or abnormal scores were assessed further using a structured interview, based on the International Classification for Disease-10 research criteria.

\section{Results}

The mean age of participants was 8.1 years and 141 (56.4\%) were males. The mean duration of asthma and age at diagnosis was 4.4 years and 3.6 years respectively. In $62 \%$ of participants, the asthma was well controlled. The prevalence of mental health problems was $8 \%$. Borderline or abnormal scores in at least one scale of the SDQ was found in $18.4 \%$, and $2.8 \%$ had abnormal or borderline impact scores. The level of asthma control was significantly associated with emotional problems score (OR 8.23, $\mathrm{p}=0.41$ ).

\section{Conclusions}

The prevalence of mental health problems among children with asthma was comparable to the general population. Asthma control was significantly associated with emotional problems and this carries implications for management.

Key words: asthma, children, mental health, emotional and behavioural problems

SL J Psychiatry 2020; 11(1): 52-57

\section{Introduction}

Asthma is one of the most common chronic diseases among children, and the prevalence in Sri Lankan children is about $20 \%(1,2)$. Several studies have demonstrated a relationship between asthma and psychological problems, with higher rates of depression, attention deficit hyperactivity disorder, anxiety disorders and behavioural disorders being reported in this group (3-7).

The specificity and temporal association between asthma and psychiatric disorders is not established, and emerging evidence points towards a more complex interaction than previously suspected $(8,9)$. Several sociodemographic and disease related characteristics impose a higher risk of psychological burden in asthma. These include low socio-economic status, negative life change, high illness severity and higher levels of activity restriction $(7,10)$. Elevated levels of utilization of both in-patient and out-patient medical services is linked with higher psychological morbidity (11).

Despite strong evidence for increased psychiatric morbidity in asthma, rates of diagnosis of mental health disorders in this group of patients are low, with rates of active treatment being lower than $20 \%(12,13)$. These children present to general paediatric settings, where the severity of the psychological impact of the disorder is at risk of being overlooked, both due to attention being directed towards the physical condition and due to lack of trained personnel. However, identification and management are important to ensure optimal quality of life and will also impact favourably on asthma control (14). 
To the best of the authors knowledge, there are no published studies in Sri Lanka to assess the prevalence of psychological problems in childhood asthma. The objectives of the current study were to describe the prevalence and factors associated with presence of emotional and behavioural problems among children with asthma.

\section{Methods}

A cross sectional descriptive study was conducted in outpatient medical clinics at Lady Ridgeway Hospital, Colombo from May to October 2015. Systematic sampling was used to select 250 participants, with sample size calculation being based on available data on prevalence (4). Children aged 6-12 years, with a diagnosis of asthma for more than six months, and who were prescribed inhaled corticosteroids were considered eligible for inclusion in the study. Children with comorbid medical illnesses, moderate to severe mental retardation or autism spectrum disorder were excluded from the study.

A specifically designed questionnaire was used to collect socio-demographic information, and clinical information on the diagnosis, treatment of asthma and level of asthma control (as per the Global Initiative for Asthma guidelines) (15). The Global Initiative for Asthma guidelines utilizes four questions related to asthma symptoms over the preceding 4 weeks; day time symptoms, night time symptoms, need for reliever medication and activity limitation due to asthma symptoms. Based on this assessment the child's asthma is categorized as being well controlled, partly controlled or poorly controlled.

The parent completed Strengths and Difficulties Questionnaire (SDQ - Sinhalese version) was administered (16). The SDQ is a widely used screening questionnaire for emotional and behavioural problems in children and is validated internationally for children aged 5-16 years (17). The Sinhalese parent completed version of the SDQ has been validated for use in Sri Lanka (18). It consists of a total of 25 questions, which are scored as 5 scales (emotional problems scale, conduct problems scale, hyperactivity scale, peer problems scale and prosocial scale). The total difficulties score is calculated by adding up the scales except the prosocial scale. For each individual scale, the score can range from 0 to 10 , and for the total difficulties score, the range is 0 to 40 . These values are categorized as normal, borderline or abnormal.

Children with borderline or abnormal scores in the individual scales of the SDQ were assessed for the presence of any psychiatric disorder, by a consultant psychiatrist or a senior registrar in psychiatry. This clinical assessment was conducted using a structured interview prepared according to ICD-10 research criteria (19). This was pilot tested among 10 children admitted to hospital with asthma exacerbations, prior to conducting the study.
During the pilot interviews, children were requested to provide feedback on whether they had any difficulties understanding or answering the questions, and this feedback was used to modify the structured interview.

Data were analyzed using the Statistical Package for Social Sciences (SPSS 21.0). Chi-square test and multinomial logistic regression analysis were used to check for associations between variables.

\section{Ethics}

Ethics approval for the study was obtained from the Ethics Review Committee of Lady Ridgeway Hospital for Children, Colombo. Informed written consent was sought from parents or legal guardians after providing both verbal and written information, prior to including the children in the study.

\section{Results}

\section{Demographic and clinical data}

The mean age of participants was 8.05 years and a majority $(56.4 \%, \mathrm{n}=141)$ were males. Most mothers $(65.2 \%, n=63)$ and fathers $(66.4 \%, n=166)$ had a secondary level education (Grade 6 to G.C.E. Ordinary Level). The mean monthly family income was Rs. 30,533.68. The monthly income was categorized for further analysis (Table 1), according to the median monthly income (Rs 30,814) of Sri Lanka as calculated by the Household Income and Expenditure Survey 2012/2013 conducted by the Department of Census and Statistics, Ministry of Finance and Planning, Sri Lanka (20).

When the fathers' occupation was categorized according to the International Standard Classification of Occupations 2008 (ISCO-08) of the International Labour Organization, plant and machine operators and assemblers accounted for $25.6 \%(n=64)$, while $20 \%(n=50)$ were service and sales workers or held elementary occupations, respectively (21). Most mothers (82.8\%, $\mathrm{n}=207$ ) were housewives.

The mean duration of asthma was 4.4 years and ranged from 0.5 to 11.5 years. The mean age at diagnosis was 3.6 years and the mean duration of inhaler use was 2.5 years. A majority of participants $(85.2 \%, n=213)$ were on a combination of beclomethasone and salbutamol inhalers. In 155 (62\%), the asthma was well controlled.

\section{Prevalence of mental health problems}

Overall, 46 children (18.4\%) in the sample had borderline or abnormal scores in at least one of emotional problems scale, conduct problems scale, hyperactivity scale, peer problems scale or total difficulties scale. Based on the findings of the structured clinical interviews, nine met criteria for hyperkinetic disorder and one met criteria for a depressive episode. 


\begin{tabular}{|c|c|}
\hline & Frequency (percentage) \\
\hline \multicolumn{2}{|l|}{ Age } \\
\hline $6-7$ years & $133(53.2 \%)$ \\
\hline $8-10$ years & $78(31.2 \%)$ \\
\hline $11-12$ years & $39(15.6 \%)$ \\
\hline \multicolumn{2}{|l|}{ Sex } \\
\hline Male & $141(56.4 \%)$ \\
\hline Female & $109(43.6 \%)$ \\
\hline \multicolumn{2}{|l|}{ School grade } \\
\hline 1 & $92(36.8 \%)$ \\
\hline 2 & $33(13.2 \%)$ \\
\hline 3 & 27 (10.8\%) \\
\hline 4 & $22(8.8 \%)$ \\
\hline 5 & $30(12 \%)$ \\
\hline 6 & $25(10 \%)$ \\
\hline 7 & $18(7.2 \%)$ \\
\hline 8 & $3(1.2 \%)$ \\
\hline \multicolumn{2}{|l|}{ District of residence } \\
\hline Colombo & $214(85.6 \%)$ \\
\hline Gampaha & $18(7.2 \%)$ \\
\hline Kaluthara & $6(2.4 \%)$ \\
\hline Other & $12(4.8 \%)$ \\
\hline \multicolumn{2}{|l|}{ Ethnicity } \\
\hline Sinhalese & $197(78.8 \%)$ \\
\hline Muslim & $32(12.8 \%)$ \\
\hline Tamil & $21(8.4 \%)$ \\
\hline \multicolumn{2}{|l|}{ Religion } \\
\hline Buddhism & $176(70.4 \%)$ \\
\hline Christianity & $32(12.8 \%)$ \\
\hline Islam & $32(12.8 \%)$ \\
\hline Hinduism & $10(4 \%)$ \\
\hline \multicolumn{2}{|l|}{ Father's level of education } \\
\hline No formal education & $2(0.8 \%)$ \\
\hline Grade 1 to 5 & $10(4 \%)$ \\
\hline Grade 6 to G.C.E. (O/L) & $166(66.4 \%)$ \\
\hline G.C.E. (A/L) & $50(20 \%)$ \\
\hline Diploma/Degree & $7(2.8 \%)$ \\
\hline Data not available & $15(6 \%)$ \\
\hline \multicolumn{2}{|l|}{ Mother's level of education } \\
\hline No formal education & $4(1.6 \%)$ \\
\hline Grade 1 to 5 & $12(4.8 \%)$ \\
\hline Grade 6 to G.C.E. (O/L) & $163(65.2 \%)$ \\
\hline G.C.E. (A/L) & $62(24.8 \%)$ \\
\hline Diploma/Degree & $5(2 \%)$ \\
\hline Data not available & $4(1.6 \%)$ \\
\hline \multicolumn{2}{|l|}{ Monthly household income (Rupees) } \\
\hline$<30,814$ & $133(53.2 \%)$ \\
\hline$>30,814$ & $60(24 \%)$ \\
\hline Data not available & $57(22.8 \%)$ \\
\hline
\end{tabular}


Parents of 35 children reported that their children had difficulties in the areas of emotions, concentration, behaviour or in getting along with other people of the impact score. Out of these children, 7 had scores in the abnormal or borderline range in the impact score. Parents of 24 children felt that these difficulties placed a burden on themselves or the family as a whole.

Children with 'abnormal' scores in one or more scales of the SDQ were considered as having emotional and behavioural problems and these results were used to calculate prevalence of these problems. Twenty children in the sample had one or more 'abnormal' scores and the calculated prevalence of emotional and behavioural problems in children with asthma was 8\% (95\% CI 5.24\%$12.03 \%)$.

\section{Factors affecting prevalence of mental health problems}

A statistically significant association was found between the mother's level of education and the child's emotional problems score $(\mathrm{p}=0.004)$. However, this association was not found to be significant when corrected for confounding variables. There were no significant associations between other socio-demographic factors (age, sex, father's education and monthly family income) and the different categories (normal, borderline and abnormal) of SDQ scores.

There were no significant associations between the duration of bronchial asthma or age at diagnosis, with SDQ scores. A statistically significant association was present between the level of asthma control and emotional problems score $(\mathrm{p}=0.047)$, which remained significant when corrected for confounding variables $(p=0.044)$.

\section{Discussion}

\section{Prevalence of mental health problems}

The prevalence of mental health problems in children with asthma was $8 \%$ in this study. This is lower than the findings of previous studies among children with asthma, but compatible with rates in the normal population $(4,11,22)$. Previous studies have shown that in children whose asthma was controlled, the prevalence rates of mental health problems are not increased above the normal population, and a majority (86\%) of children in the current study had well controlled or partially controlled asthma $(23,24)$.

\section{Association with socio-demographic and clinical characteristics}

In this study, the level of asthma control was found to be significantly associated with emotional problems score after controlling for confounding variables. This finding is compatible with several previous studies $(7,25)$.
Previous work has reported that socio-economic disadvantages and being female are significantly associated with psychological comorbidity in asthma $(4,7,10)$. However, the present study did not show a significant association with indicators of socio-economic status, which could reflect other characteristics of families seeking care at this setting.

There was no significant association between the duration of asthma and prevalence of emotional and behavioural problems in this study. However, in a previous study, the duration of bronchial asthma was positively associated with mental and behavioural problems, with children having asthma for more than 4 years being at increased risk (26).

No significant association was found between the age of diagnosis of asthma and mental health problems. A longitudinal prospective study of 150 children from birth to 6 years found that onset of asthma by 3 years of age was associated with significantly more behavioural problems (27). Because of difficulties in determining age of onset retrospectively, the current study used the age at diagnosis of asthma.

\section{Limitations}

Limitations in generalizing the findings of this study may arise due to the study setting, use of only the parent completed version of SDQ due to resource limitations and the fact that other effects, such as parental characteristics (substance use, mental illness, parenting style) and other family factors (number of children, number of people in the household), were not assessed. However, attempts were made to minimize confounding effects by excluding children with comorbid chronic medical illnesses, mental retardation and autism spectrum disorder.

This study was done in an out-patient clinic at a specialized children's hospital. These clinics cater to a large number of patients from all districts of the country, as this is the final referral children's hospital in Sri Lanka, and there is no selection of patients depending on area of residence, other socio-demographic characteristics or past treatment. Thus, the participants in this sample may have deferred from children with asthma managed in primary care settings, including characteristics such as severity of asthma, knowledge and attitudes towards asthma and its management, and help seeking behaviours.

\section{Conclusions}

Eight percent of the children with asthma on long term inhaled corticosteroids, attending out-patient follow up clinics had emotional and behavioural problems. The prevalence of mental health problems among children with asthma in this study was comparable to the general 
population. Socio-demographic factors were not significantly associated with psychological problems. The level of asthma control was significantly associated with the occurrence of emotional problems.

There is a need for further studies in the local population in different settings (community, primary care and inpatient). The significant association found between emotional problems and level of asthma control carries implications for the management of asthma. Development of awareness and skills among medical personnel in general paediatric settings would enable assessment and management of psychological problems among children with poor asthma control, which would ultimately ensure better health care and enhanced quality of life for these children.

\section{Acknowledgments}

The authors would like to acknowledge the support of Dr Thilanga Ruwanpathirana (Consultant Epidemiologist) for data analysis.

\section{Conflicts of interest}

None declared.

DMA Dahanayake, GS Wijetunge, Lady Ridgeway Hospital for Children, Colombo, Sri Lanka

VA de Silva, Faculty of Medicine, University of Colombo, Sri Lanka

Corresponding author: DMA Dahanayake

Email: dulangid@yahoo.com

http://orcid.org/0000-0002-1740-2183

\section{References}

1. World Health Organization. Chronic respiratory diseases [Internet]. Geneva; World Health Organization; 2017 [cited 2017 October 20]. Available from: http://www.who.int/ mediacentre/factsheets/fs307/en/

2. Karunasekera KAW, Perera KPJ, Perera MTPR, Abeynarayana J. Prevalence of asthma and atopic symptoms in children aged 5-11 years. Sri Lanka Journal of Child Health 2003; 32: 11-14.

3. McQuaid EL, Kopel SJ, Nassau JH. Behavioural adjustment in children with asthma: a meta-analysis. J Dev Behav Pediatr 2001; 22: 430-9.

4. Alvim CG, Ricas J, Camargos PAM, Lasmar LMBF, de Andrade CC, Ibiapina CR. Prevalence of emotional and behavioural disorders in adolescents with asthma. J Bras Pneumol 2008; 34: 196-204.
5. Bennett DS. Depression among children with chronic medical problems: a meta-analysis. J Pediatr Psychol 1994; 19: $149-69$.

6. Miller B. Depression and asthma: a potentially lethal mixture. J Allergy Clin Immunol 1987; 80: 481-6.

7. Blackman JA, Gurka MJ. Developmental and behavioural comorbidities of asthma in children. J Dev Behav Pediatr 2007; 28(2): 92-9.

8. Ortego AN, Huertas SE, Canino G, Ramirez R, RubioStipec M. Childhood asthma, chronic illness, and psychiatric disorders. J Nerv Ment Dis 2002; 190: 275-81.

9. Van Lieshout RJ, MacQueen G. Psychological factors in asthma. J Allergy Clin Immunol 2008; 4(1): 12-28.

10. MacLean WE, Perrin JM, Gortmaker S, Pierre CB. Psychological adjustment of children with asthma: effects of illness severity and recent stressful life events. J Pediatr Psychol 1992; 17: 159-71.

11. Goodwin RD, Messineo K, Bregante A, Hoven CW, Kairam R. Prevalence of probable mental disorders among paediatric asthma patients in an inner-city clinic. J Asthma 2005; 42: 643-7.

12. Katon WJ, Richardson L, Russo J. Quality of mental health care for youth with asthma and comorbid anxiety and depression. Med Care 2006; 44: 1064-72.

13. Kelleher KJ, Horwitz SM. Quality of mental health care for children: a familiar storyline. Med Care 2006; 44: 1061-3.

14. Van Lieshout RJ, MacQueen GM. Relations between asthma and psychological distress: an old idea revisited. Chem Immunol Allergy 2012; 98: 1-13.

15. Global Initiative for Asthma (GINA). Pocket Guide for Asthma Management and Prevention. Fontana, WI: GINA; 2019. p. 12.

16. Youth in mind. Information for researchers and professionals about the Strengths \& Difficulties Questionnaires [Internet]. 2014 [cited 2015 March 10]. Available from: http://www.sdqinfo.com/py/sdqinfo/ b3.py?language $=$ Sinhalese

17. Goodman A, Goodman R. Strengths and difficulties questionnaire as a dimensional measure of child mental health. J Am Acad Child Adolesc Psychiatry 2009; 48: 400-3.

18. Perera S, Thalagala E, Chandrarathna SH, Agampodi TC, Nugegoda DB, Agampodi SB. Factor structure and normative data of the Sinhalese version of self reported Strengths and Difficulties Questionnaire (SDQ) for adolescents. Ceylon Med J 2013; 58: 66-71.

19. The ICD-10 Classification of Mental and Behavioural Disorders - Diagnostic criteria for research. Geneva: World Health Organization;1993. 
20. Department of Census and Statistics. Household Income and Expenditure Survey 2012/2013. Colombo (SL): Department of Census and Statistics; 2015. p. 111.

21. International Labour Organization. International Standard Classification of Occupations 2008 (ISCO-08) [Internet] 2008 [updated 2016 June 21; cited 2016 Nov 15]. Available from: http://www.ilo.org/public/english/bureau/stat/isco/ intro3.htm

22. Perera H, Gunatunge C. Screening for mental health problems in urban preschool children - a pilot study. Sri Lanka Journal of Child Health 2004; 33: 39-42.

23. Calam R, Gregg L, Goodman R. Psychological adjustment and asthma in children and adolescents: the UK nationwide mental health survey. Psychosom Med 2005; 67: 105-10.
24. Letitre SL, de Groot EP, Draaisma E, Brand PL. Anxiety, depression and self-esteem in children with well-controlled asthma: case-control study. Arch Dis Child 2014; 99: 744-8.

25. Lavoie KL, Cartier A, Labrecque $\mathrm{M}$ et al. Are psychiatric disorders associated with worse asthma control and quality of life in asthma patients? Respir Med 2005; 99: 1249-57.

26. Macri F, Rossi FP, Lambiase C, di Castelbianco FB, Frassanito A. Psychological factors in childhood asthma. Pediatr Pulmonol 2008; 43: 366-70.

27. Mrazek DA, Schuman WB, Klinnert M. Early asthma onset: risk of emotional and behavioural difficulties. J Child Psychol Psychiatry 1998; 39: 247-54. 